\title{
Role of Ergonomics and Innovation during Covid-19 Pandemic
}

\author{
Pandve $\mathrm{HT}^{*}$ \\ Department of Community Medicine, ESIC Medical College, India
}

\section{Editorial}

Volume 4 Issue 3

Received Date: May 20, 2020

Published Date: June 09, 2020

DOI: $10.23880 /$ eoij-16000238

*Corresponding author: Harshal Tukaram Pandve, Professor \& Head, Department of Community Medicine, ESIC Medical College, Hyderabad, India, Email: dr.harshalpandve@ gmail.com

\section{Editorial}

Ergonomics is defined as an applied science concerned with designing and arranging things people use so that the people and things interact most efficiently and safely [1]. Another definition stated that ergonomics is the scientific study of people and their working conditions, especially done in order to improve effectiveness [2]. As per International Ergonomics Association "Ergonomics is the scientific discipline concerned with the understanding of interactions among humans and other elements of a system, and the profession that applies theory, principles, data and methods to design in order to optimise human well-being and overall system performance." Ergonomics is a sciencebased discipline that brings together knowledge from other subjects such as anatomy and physiology, psychology, engineering and statistics to ensure that designs complement the strengths and abilities of people and minimise the effects of their limitations [3]. Along with ergonomics another terminology is also important that is innovations. Innovation is the process of translating an idea or invention into a service that creates value is revenue-generating to be selfsustaining.

The novel coronavirus disease (COVID-19) that emerged at the end of 2019 began threatening the health of millions of people. World Health Organization has declared COVID-19 pandemic as public health emergency of national and international concern. With COVID-19 pandemic tightening its grip, for healthcare workers who are at the forefront of the battle, ergonomics innovations become much more essential compared to past. Some of the innovation is already in place such as contactless screening devices to enable automatic detection of health symptoms, contactless sample collection booths, contactless sanitizer dispensers, use of information technology in contact tracing which is really commendable. Still many ergonomics innovations are needed to make working of health care workers safer as well as comfortable. For an example, Ergonomics innovators mainly need to focus on Personal Protective Equipment (PPEs) which are safe as well as comfortable while working in hot and humid conditions as it is really difficult to use PPEs for 3 to 4 hours in such conditions. Another challenge which Ergonomics experts need to focus on is related to people who are working from home due to lock-down. As homes are converted into offices for many in this COVID-19 pandemic, it is important to spread awareness regarding proper ergonomics practices to avoid any health issues in future. For example using proper chairs, locations for working for long hours at home.

To conclude with, experts in the fields of ergonomics and innovations need to work for the safety of healthcare providers as well as workers working from homes who are exposed to various occupational hazards while working in the pandemic situation. This COVID-19 pandemic has provided opportunities for to explore many possibilities in the field of Ergonomics and Innovations.

\section{References}

1. https://www.merriam-webster.com/dictionary/ ergonomics

2. https://dictionary.cambridge.org/dictionary/english/ ergonomics

3. What is ergonomics? 